\title{
Diagnostic management of cheilitis: an approach based on a recent proposal for cheilitis classification
}

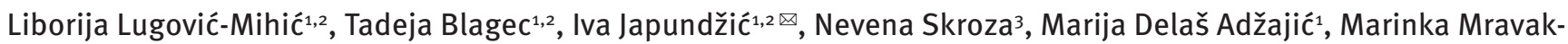 \\ Stipetić ${ }^{2,4}$
}

${ }^{1}$ Department of Dermatovenereology, University Hospital Center Sestre Milosrdnice, Zagreb, Croatia. ${ }^{2}$ School of Dental Medicine, University of Zagreb,

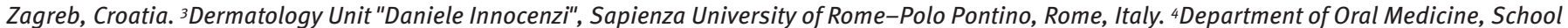
of Dental Medicine, University of Zagreb, Zagreb, Croatia.

\begin{abstract}
Currently, there are no clear recommendations for diagnostic management of lip inflammation and cheilitis, which is evident in the varied nomenclature and subtypes found in medical literature on cheilitis. This can confound diagnostic management. We therefore recently put forth a proposal for cheilitis classification, defining three groups of cheilitis based on duration and etiology: mainly reversible cheilitis, mainly irreversible cheilitis, and cheilitis connected to other diseases. The most common forms of cheilitis are the reversible types, usually of short duration and commonly easily resolved or treated. In contrast, irreversible types of cheilitis are rare, are harder to treat, and are confirmed only after a biopsy of an inflamed lesion. To correctly diagnose and manage the different types, practitioners must consider several factors, including visible manifestations of the disease, related diseases and symptoms, personal habits, weather conditions, allergies, nutritional deficiencies, and results from tissue swabs and biopsies. In addition, multispecialty collaboration and communication involving dermatology, oral pathology, clinical immunology, otorhinolaryngology, rheumatology, and other fields can be crucial for patient outcome. We believe our classification system would be of great benefit to researchers, patients, and doctors by simplifying both nomenclature and disease recognition, thus ensuring timely and adequate treatment.
\end{abstract}

Keywords: cheilitis, classification, lips, diagnosis, management, lip inflammation

Received: 11 February 2020 | Returned for modification: 30 March 2020 | Accepted: 20 April 2020

\section{Introduction}

Cheilitis is a lip inflammation that sometimes spreads to the surrounding skin and oral mucosa. It has various manifestations and can be transient, reversible, or persistent (1-3). Many factors can be involved in the disease's development, such as an atopic constitution, contact irritants or allergens, chronic sun exposure, and infection. The lips may also become involved secondarily during many cutaneous diseases (e.g., lichen planus, angioedema, autoimmune blistering diseases, etc.) or systemic disorders (Sjögren syndrome, sarcoidosis, etc.) (1-4).

Many types of cheilitis exist, and there are no clear recommendations for classification (3-10). However, the most commonly mentioned forms are actinic, angular, contact allergic, exfoliative, glandular, granulomatous, and plasma cell cheilitis. In order to create a more useful guideline for diagnosis, we recently published a proposed classification of cheilitis that includes three groups based on the duration and etiology of the disease: mainly reversible cheilitis, mainly irreversible cheilitis, and cheilitis connected to dermatoses and systemic diseases (1). This simplified classification is easier to remember and use in practical work, and it may be helpful for determining diagnostic approaches to patients with lip inflammation. We hope a clear system ultimately leads to a more timely diagnosis and treatment.

\section{Literature data regarding cheilitis types and classification}

Various cheilitis types and classifications are found in the litera- ture (Table 1) (1-12). High-profile dermatological literature names only a few of the most common types, though some expanded classifications exist (4). Most of the literature does not actually use the word classification, but groups cheilitis into different types based on specific features, such as frequency. Thus, in the literature we found only classifications based on the frequency of cheilitis in which authors identify common types of cheilitis (actinic cheilitis, irritant contact dermatitis, and atopic dermatitis [AD]), less common types (allergic contact dermatitis, candidal cheilitis, lichen planus and graft versus host disease [GVHD], and granulomatous cheilitis), and uncommon types (glandularis, actinic prurigo, lichen sclerosus, and nutritional deficiencies) (9). In other literature, authors label different types as chapping of the lips, eczematous, contact, drug-induced, infective, angular, actinic, glandular, granulomatous, exfoliative (factitious), plasma cell, nutritional, and cheilitis caused by dermatoses and trauma (10). In addition, some authors mention classification according to etiology: lip inflammation types can be separated into those due to infection, allergy, a toxin, medication, or injury, or due to a vitamin or mineral deficiency (iron or vitamin B) (7). Our recently published proposal provides a thorough but more succinct way to group different forms of cheilitis by classifying the disease, as previously mentioned, into three main types according to duration and etiology (1). The most common forms of cheilitis are the reversible types, usually of short duration and commonly easily resolved or treated. On the other hand, irreversible types of cheilitis are rare, more difficult to treat, and confirmed only after a biopsy of an inflamed lesion. The third type is cheilitis connected to other cutaneous/systemic diseases. 
In practice, the approach to diagnostics can be complicated by many etiologies and causes of cheilitis $(1-4,11)$. Thus, cheilitis may be related to the previous occurrence of a systemic condition or disease such as oral candidiasis, diabetes, or a nutritional deficiency (e.g., megaloblastic anemia due to vitamin B12 deficiency, or anemia due to iron deficiency) $(1,3,4,7,13)$. Concomitant/ related cutaneous or systemic diseases may also come into play, such as AD, lupus erythematosus (LE), or lichen planus. Moreover, in contact cheilitis, for example, practitioners must look at substances that may cause irritative or allergic effects or reactions on the lips (1-3). Other external etiological factors are also important, such as weather conditions, habits such as lip licking and biting, and excessive sun exposure (3, 4, 7, 13-15). A patient history should also consider that each type of cheilitis has its own list of triggers that are more common to it than to other forms. For example, angular cheilitis is frequently associated with excessive moisture, irritations, nutritional deficiencies, and infections of angular lip skin, whereas contact/eczematous cheilitis is related to exogenous factors such as contact irritants or allergens.

Finally, cheilitis is a disease that involves various branches of medicine and belongs to various specialties, thus requiring a multidisciplinary approach. This additionally complicates approaches to diagnostics and the adoption of a classification system. However, accurately recognizing the type of cheilitis in question and confirming and addressing its causes can be crucial for regression of the disease.

\section{Characteristics of predominantly reversible cheilitis}

Our proposed classification first identifies reversible cheilitis as one of three main groups of cheilitis (Fig. 1). This group comprises five main types, which are often of a temporary nature.

Cheilitis simplex (common cheilitis, chapped lips, cheilitis sicca) is a common type of reversible cheilitis (this name is often used as a synonym for cheilitis in general). Its manifestations, usually appearing on the lower lip, are cracked lips, lip fissures, or desquamation (Fig. 1A) (1, 4, 14-16). In addition to lip lesions, burning sensations and painful fissures are possible. If changes persist, crusts or bleeding can occur (15). Sometimes it is difficult to differentiate cheilitis simplex from actinic cheilitis by clinical picture alone, especially when crusts, fissures, or ulcers are present. In these cases, a detailed patient history is crucial for an accurate diagnosis. For example, long duration of lip lesions and long sun exposure seen in a patient's medical history could indicate that a biopsy would be useful for excluding actinic cheilitis. In cheilitis simplex, frequent triggers and causes are lip licking, especially in cheilitis with $\mathrm{AD}$, repeated lip biting (cheilophagia), or wiping habits $(4,13-15)$. Another important influence on cheilitis development is climate. During cold, windy, and dry weather, lips are prone to dryness, and the accompanying salivary moistening of the lips only worsens the disease (4-8).

Angular/infective cheilitis usually appears in the corners of the lips, commonly as a two-sided inflammation with erythema, deep fissures, or laceration of the labial commissure, possibly with shallow ulcers or crusts (16-18). There are numerous related and
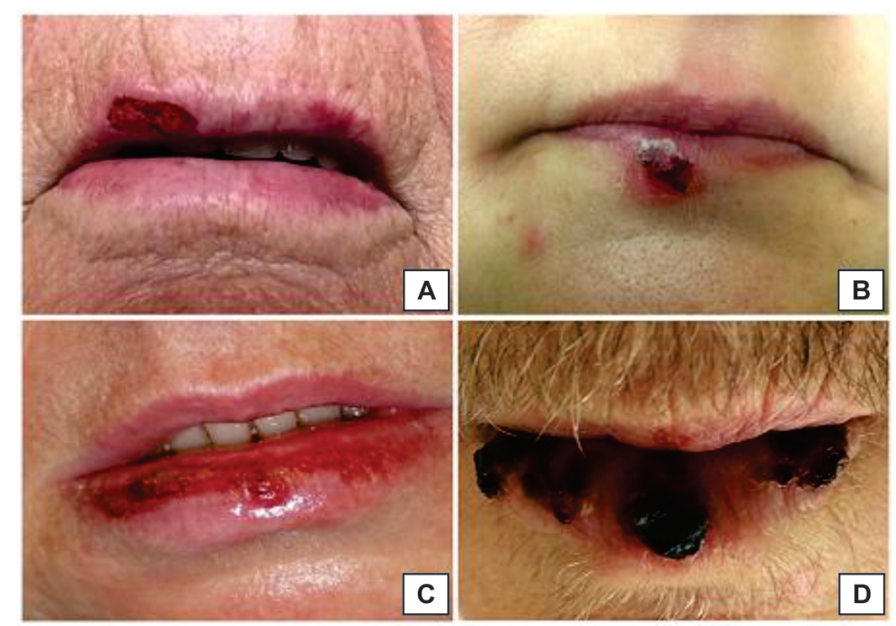

Figure 1 | Mainly reversible types of cheilitis ( $A=$ cheilitis simplex; $B=$ infective (herpetic) cheilitis; $C=$ contact/eczematous cheilitis; $D=$ drug-related cheilitis).

Table 1 | Cheilitis types according to different literature data.

\begin{tabular}{|c|c|}
\hline Source & Types \\
\hline Bork K. (Braun-Falco’s dermatology) (4) & $\begin{array}{l}\text { - Angular; simplex; actinic (acute/chronic); glandularis; granulomatous; plasma cell } \\
\text { cheilitis }\end{array}$ \\
\hline Cohen DE, de Souza A. (Dermatology) (9) & 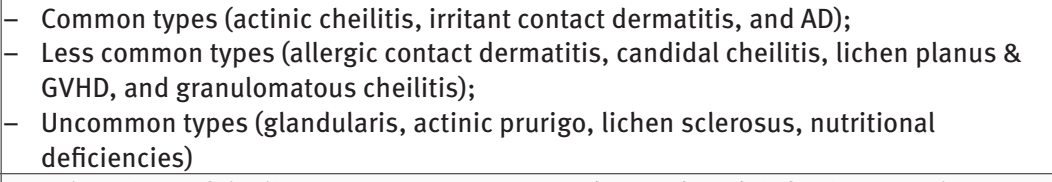 \\
\hline Scully C. (Rook's textbook of dermatology) (10) & $\begin{array}{l}\text { - “Chapping” of the lips; eczematous; contact; drug-induced; infective; angular; } \\
\text { actinic; glandular; granulomatous; exfoliative (factitious); plasma cell; due to } \\
\text { nutritional factors; due to dermatoses; due to trauma }\end{array}$ \\
\hline Woo SB. (Fitzpatrick's dermatology in general medicine) (12) & - Actinic; granulomatosa; angular; exfoliative; allergic (or irritant) contact cheilitis \\
\hline Mowad C. (UpToDate) (2) & $\begin{array}{l}\text { - Eczematous (irritant contact, allergic contact, atopic); actinic; angular; plasma cell; } \\
\text { glandularis; granulomatosa }\end{array}$ \\
\hline Oakley A, et al. (DermNet NZ) (7) & $\begin{array}{l}\text { - Due to infection or skin conditions: angular, granulomatous, orofacial } \\
\text { granulomatosis, Crohn's skin disease, actinic, exfoliative, lichenoid, cutaneous LE; } \\
\text { - Due to an allergy, due to toxin and medication influence or injury (eczematous } \\
\text { cheilitis, allergic contact cheilitis, pigmented contact cheilitis, cheilitis in musicians, } \\
\text { irritant and allergic contact dermatitis, smoking and its effects on the skin, sunburn, } \\
\text { isotretinoin treatment, acitretin treatment, denture stomatitis); } \\
\text { - Due to due to nutritional deficiency (iron, vitamin } B_{12} \text { ) }\end{array}$ \\
\hline Lugović-Mihić L, et al. (Acta Clin Croat) (1) & $\begin{array}{l}\text { - Mainly reversible (simplex, angular/infective, contact/eczematous, exfoliative, drug- } \\
\text { related); } \\
\text { - } \text { Mainly irreversible (actinic, granulomatous, glandular, plasma cell); } \\
\text { - } \text { Cheilitis connected to dermatoses and systemic diseases (lupus, lichen planus, } \\
\text { pemphigus/pemphigoid group, angioedema, xerostomia, etc.) }\end{array}$ \\
\hline
\end{tabular}

$\mathrm{AD}=$ atopic dermatitis, GVHD = graft versus host disease, $\mathrm{LE}=$ lupus erythematosus. 
causative factors, such as infections (Candida spp. and Staphylococcus spp.), nutritional deficiencies (e.g., B vitamins, zinc, and iron), primary hypervitaminosis A, type 2 diabetes, medications, psychiatric diseases (e.g., anorexia nervosa and bulimia), time of year (winter), old age (existing channels on lip commissures, tooth loss, or inadequate dentures), and inflammatory bowel diseases (e.g. Crohn's disease or ulcerative colitis) (1-4, 11, 19-24). A primary bacterial or candidiasis infection can occur, mostly unilaterally and often in patients with HIV and suppressed immune systems, during long-term antibiotic and corticosteroid therapy or after trauma or physical stretching (e.g., following a dental procedure). Secondary infections occur frequently in children, especially children that suffer from AD. Sometimes, angular cheilitis lesions are associated with manifestations of Plummer-Vinson syndrome, such as atrophic glossitis, dysphagia, and esophageal webbing within iron deficiency anemia syndrome $(1,25)$. In diagnostics, an analysis of a lesional swab with potassium hydroxide $(\mathrm{KOH})$ can reveal a possible fungal infection.

Aside from bacterial or fungal infections, another especially frequent trigger of infective cheilitis is the herpes simplex virus (HSV) $(11,26)$. This type of cheilitis often appears with mild clinical manifestations on the lips and perioral region that include clear, grouped papules and vesicles that form crusts as they erode and then disappear (Fig. 1B). With this form, recurrent herpes labialis is very common, and this form of cheilitis has many triggers, including psychological stress, trauma, menstruation, drugs, and UV light. Other viral infections can also appear on the lips such as human papillomavirus, which causes verrucous papules. Molluscum contagiosum, however, caused by a virus of the Poxviridae family, can also trigger cheilitis but very rarely occurs on the lips and presents with umbilicated papules (11).

Contact/eczematous cheilitis is a common cheilitis manifesting with erythematous lesions and scales that sometimes extend to the perioral or oral regions, commonly with pruritus and burning (Fig $1 \mathrm{C}$ ). Eczematous cheilitis can be caused by both endogenous (e.g., AD) or exogenous factors such as contact irritants or allergens (27-35). For some patients there may be multiple causes and triggers $(2,4,28,29)$. Thus, many products exist that could provoke a reaction, such as foods, oral hygiene products, or dental materials; specifically, ingredients in these products such as antioxidants, ointment bases, fragrances, preservatives, and dyes. Other causative objects can include musical or occupational instruments, lipsticks, or other things that might be put in the mouth on a daily basis such as fingernails or pens $(1,14,30)$. In this type, there are three subtypes of cheilitis that have similar clinical pictures (irritant contact, allergic contact, and atopic), making it difficult to diagnose them without testing. The most frequent among them is irritant (non-allergic) contact cheilitis, which may be caused by substances that often cause irritations, chronic lip-licking, particularly in young children, and a variety of environmental etiologies $(1-3,14,31)$. Allergic contact cheilitis, another subtype, occurs more in women, probably due to greater cosmetics use (1, 2, 27, 29, 31). The allergens include cosmetic sensitizers (fragrances, Myroxylon balsamum var. pereirae, and nickel), ingredients unique to lipsticks (e.g., ricinoleic acid, also known as castor oil), resins (e.g., rosin and shellac), dyes in drugs and cosmetics, preservatives, copolymers, ozonated olive oil, and propolis (2, 32-34). Clinically, allergic contact cheilitis typically manifests with lip erythema and concomitant desquamation, which may spread to surrounding skin, frequently with concomitant pruritus, burning, and tenderness (2). Atopic cheilitis, the third subtype, presents with erythema, dryness, scaling, and fissuring (1). This form appears in $\mathrm{AD}$ patients and is in fact one of the diagnostic criteria for $\mathrm{AD}$.

A diagnosis of contact/eczematous cheilitis should be based on a general skin examination and a detailed patient history that includes data on atopy and contact with irritants or allergens. When looking for causative allergens, the patch test is an invaluable method that can confirm delayed allergic reactions. According to recent patch test results by Budimir et al., the most common positive allergic contact reactions were to metals (cobalt, nickel, and mercury) (26.7\%) (35). However, according to other research data, relevant patch test reactions were found in 30 to $65 \%$ of patients tested with standard and supplementary allergen series (29-31). Generally, the most common allergens are metals, fragrances, antioxidants, and preservatives (1, 2, 28-35). These findings should be taken into consideration when diagnosing eczematous cheilitis.

Exfoliative cheilitis is characterized by persistent lip desquamation and peeling with concomitant dryness, itching, or tingling occurring mostly only on the lower lip $(11,36)$. It is not a common condition and mainly occurs in younger persons that moisturize their lips frequently or in those with B12 or iron deficiencies (1, 37). Initially the lips look normal or red, but they then develop a thickened surface layer, followed by peeling that proceeds cyclically at different rates. Bleeding can occur, leading to hemorrhagic crust formation. Many issues and habits can contribute to disease progression, including mouth breathing, lip licking and biting, infections, and poor oral hygiene (5). A diagnosis is based on a clinical picture, data on related causes, and the exclusion of other conditions. Concerning clarity around classification and nomenclature, we recommend that the term exfoliative cheilitis not be used (as has been done) as a synonym for cracked lips; this type includes a number of symptoms aside from simple cracking.

Drug-induced cheilitis, another type of reversible cheilitis, is particularly common with isotretinoin use, frequently manifesting as lip dryness and desquamation, but can also be triggered by antihypertensives, antipsychotics, anticonvulsants, antihistamines, anticholinergics, and so on (Fig. 1D). Because it is often impossible to stop taking the causative drug, supportive topical skin care such as topical emollients for the lips can ease symptoms.

\section{Characteristics of irreversible cheilitis}

This is a group of four chronic cheilitis types for which diagnoses are usually based on a biopsy and histology (Fig. 2) (1).

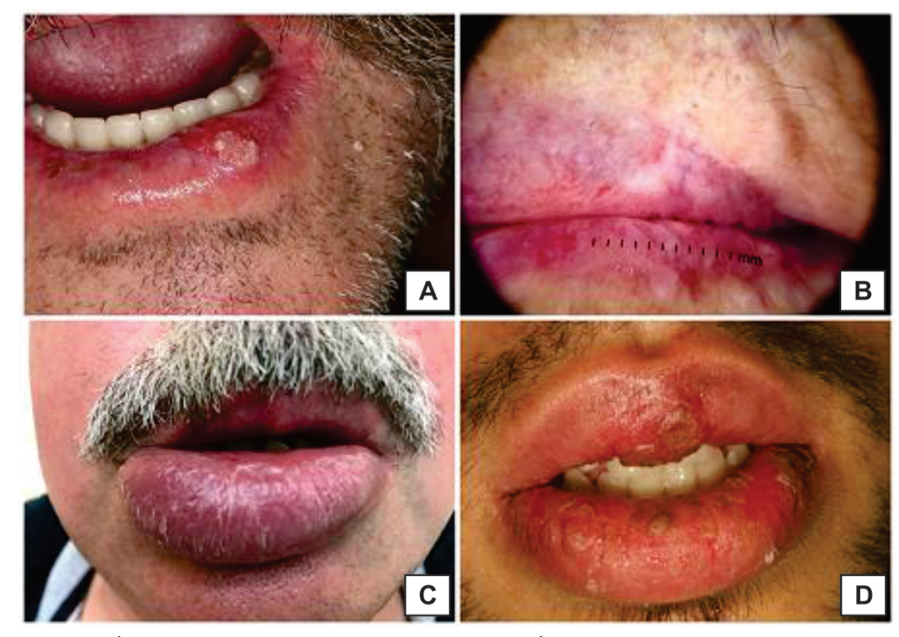

Figure 2 | Mainly irreversible types of cheilitis ( $A=$ actinic cheilitis; $B=$ dermoscopic finding of actinic cheilitis; $C=$ granulomatous cheilitis; $D=$ glandular cheilitis). 
Actinic (solar) cheilitis presents as a premalignant lip keratosis caused by chronic sun exposure (ultraviolet radiation) (Fig. 2). It occurs most commonly in geographical areas with hot, dry climates, in outdoor occupations (sailing, agriculture, construction, beach-related work, etc.), and in light-skinned individuals (skin phototype I) or those genetically more susceptible to solar damage. It also occurs commonly in older or middle-aged males, in patients suffering from $\mathrm{AD}$, or in those with actinic prurigo or LE (4). It can also be caused by smoking, lip irritation, poor oral hygiene, and poor adhesion of dentures (1, 2, 40, 42-48). Because it is a potentially malignant disorder, lesions should be biopsied to rule out severe dysplasia or squamous cell carcinoma (SCC) (3). The disease typically presents on the lower lip with a whitish discoloration and painless thickening along the edges; over time, the sharp border of the lip becomes less clear. Commonly, a dry, atrophic, erythematous, scaly, and indurated lip lesion appears, usually solitary, although multiple lesions can occur (Figs. 2A, 2B) (41).

The recognition of actinic chelitis is based on a histopathological picture that can include various findings: epithelial dysplasia, variable hyperkeratosis or atrophy and inflammatory infiltrate in connective tissue, vasodilatation, and solar elastosis (2, 42, 44, 45, 47). Sometimes many biopsies are needed for a precise diagnosis. An analysis using Fourier transform infrared spectroscopy, shown to be useful in detecting tissue changes (nucleic acids and collagen), can reveal initial cancerous lesions $(46,48)$. Concerning a differential diagnosis, actinic cheilitis may be similar to granulomatous cheilitis, SCC, glandular cheilitis, or plasma cell cheilitis.

Granulomatous cheilitis (orofacial granulomatosis or Miescher's cheilitis) manifests with lip swelling, usually persistent (Fig. 2C) (1, 3, 49-51). Its etiopathogenesis is unknown, although it may be related to various issues, including genetic predisposition, food allergies (e.g., cinnamon or benzoates), infection, and atopy $(1,2,11,49,50,52)$. Initially, there is commonly intermittent upper lip swelling; with time it leads to persistent swelling. Sometimes granulomatous cheilitis is associated with manifestations of Melkersson-Rosenthal syndrome (2, 49, 53). Granulomatous cheilitis may be similar in appearance to angioedema, oral Crohn's disease, sarcoidosis, a foreign body reaction, and infections such as tuberculosis or histoplasmosis. A diagnosis is based on a lip biopsy, which excludes other similar conditions (other diseases with oral or facial involvement) and shows edema and perivascular cell infiltrate (typical in early disease stages), which is followed by small sarcoidal granulomas, although biopsies are rarely conclusive at this stage $(4,54,55)$.

Glandular cheilitis, a very rare condition, is an inflammatory disorder of the minor salivary glands usually appearing on the lower lip and is commonly seen in older males (Fig. 2D) (1, 4, 5660 ). Although its etiology is unknown, sun exposure, poor oral hygiene, bacterial infection, and congenital predisposition are some of the factors that could be involved $(1,2)$. A possible pathogenesis lies in inadequate cell membrane transport of water and small solute because this possibly changes salivary composition $(11,60)$.

Clinically, the simplex form of glandular cheilitis usually appears as tiny red papules or lip edema, whereas glandular apostematosa is characterized by a secondary infection (Staphylococcus spp.) of the salivary glands that presents with crusts, pus drainage, and pain. Extreme cases present as severe suppurative forms, or sometimes a secondary infection can cause an abscess or other difficult manifestation $(11,60)$. The disease can also lead to potentially malignant disorders and potentially SCC. Glandular cheilitis may be similar in appearance to granulomatous cheilitis, actinic cheilitis, or SCC. A diagnosis is based on a clinical picture; the histopathology is commonly nonspecific. A confocal microscopy may also be useful (11, 60-62).

Plasma cell cheilitis is considered an oral counterpart of plasma cell balanitis and is a very rare lip inflammation. Its etiology is unknown, and it is characterized by a dense plasma cell infiltrate $(1,16,63-65)$. The disease manifests with erythematous asymptomatic plaque or slightly raised eroded areas most often located on the lower lip $(1,65)$. This type may be similar to lichen planus, allergic contact cheilitis, actinic cheilitis, SCC, or syphilis. For a diagnosis, histological findings of plasma cell infiltrate (bandlike) are necessary.

\section{Characteristics of cheilitis associated with cutaneous/systemic diseases}

It is necessary to be aware that inflammatory lesions on the lip may occur with many dermatological or systemic diseases. Thus, practitioners may want to consider and check for diseases such as LE, lichen planus, Sjögren syndrome, pemphigus and pemphigoid, and angioedema (Fig. 3). In addition, cutaneous or systemic diseases sometimes begin on oral mucosa involving the lips, and so an adequate examination of all parts of the oral mucosa and skin is necessary for appropriate management.

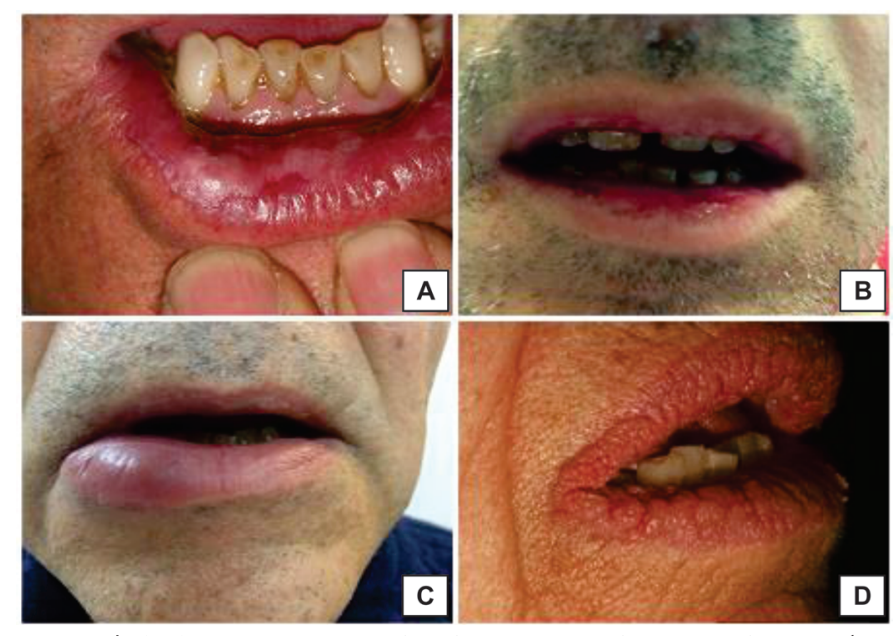

Figure 3 | Cheilitis types connected to dermatoses and systemic diseases ( $A=$ lichen planus; $B=$ pemphigus; $C=$ angioedema; $D=$ acanthosis nigricans).

LE of the lips is similar to atrophic actinic cheilitis both clinically and histologically. Discoid lupus erythematosus (DLE) usually involves the skin but may sometimes manifest with oral lesions involving the lips, predominantly the lower lip. It commonly manifests as red or white papules or plaques on the lip vermilion $(1,11,66,67)$. In systemic LE (SLE) purpuric macules, erosions, or ulcerations are observed on the lips, as well as bordered or diffuse erythema (1). Because SLE can be aggressive, a biopsy should be conducted to look for any possible malignant transformations (11).

Lichen planus typically manifests with white reticular lip lesions, which can be histologically confirmed by typical lichen findings (Civatte bodies, a band-like lymphocytic infiltrate in the upper dermis, etc.). However, when histopathological characteristics are not clear or are not found, one must rely on the clinical characteristics associated with the patient's symptoms for a diagnosis.

Sjögren syndrome is a systemic autoimmune disease of the 
salivary glands that is more common in women and is mainly characterized by dry eyes and mouth but can also involve many other organs (11). Because clinical manifestations can be nonspecific and subtle, delayed diagnoses or misdiagnoses are possible (11). A diagnosis is based on a biopsy of the salivary glands (11, 6o). Multispecialty collaboration and communication involving oral pathology, ophthalmology, clinical immunology, rheumatology, dermatology, and others can be crucial for patient outcome.

Pemphigus and pemphigoid diseases may sometimes manifest on the lips as erosions and similar lesions, which is more common in pemphigus than in pemphigoid patients $(1,68)$.

Angioedema is common on the lips and is often related to an allergy and ACE inhibitor or calcium channel blocker use. Determining the etiology and trigger is crucial for disease resolution $(1,69)$.

\section{Diagnostic and treatment approaches}

The diagnostic approach to a patient with inflammatory lip lesions must consider that there are many possible etiologies and triggers (Fig. 4). Some types are recognizable by their characteristic clinical features, such as angular, herpetic, and exfoliative cheilitis. However, most forms of cheilitis manifest with a nonspecific picture, and it is necessary for practitioners to examine the patient's general medical history (e.g., environmental conditions, undesirable habits, recent contact with substances, deficiencies, immune status, related and associated diseases, lengthy sun exposure, etc.) when establishing the final diagnosis $(1,3,11,68-$ 70). Sometimes it is also important to establish what the causative issues are, such as allergies or drugs, before making a definitive diagnosis (e.g., eczematous and drug-induced cheilitis). For patients with persistent lip inflammation, a biopsy is necessary especially for irreversible types to recognize the specific type of irreversible cheilitis and to check for potentially malignant disorders in a timely manner (70). In addition, a concomitant systemic or skin disease can also point to the form of cheilitis a patient has. An effective diagnostic approach can also be achieved when clinicians are able to refer to a clear, common classification system for cheilitis. This is especially important in cases where abnormalities or potentially malignant disorders need to be detected early to stop the spread of the disease.

\section{References}

1. Lugović-Mihić L, Pilipović K, Crnarić I, Šitum M, Duvančić T. Differential diagnosis of cheilitis-how to classify cheilitis? Acta Clin Croat. 2018;57:1-10.

2. Mowad C. Cheilitis [Internet]. 2019 [cited 2019 September 20]. Available from: http://www.uptodate.com/contents/cheilitis.

3. Samimi M. Cheilitis: diagnosis and treatment. Presse Med, 2016;45:240-50.

4. Bork K. Diseases of the lips and mouth. In: Burgdorf WHC, Plewig G, Wolf HH, Landthaler M, editors. Braun-Falco's dermatology, 3rd ed. Berlin: Springer-Verlag; 2009. p. 1081-107.

5. Almazrooa SA, Woo SB, Mawardi H, Treister N. Characterization and management of exfoliative cheilitis: a single-center experience. Oral Surg Oral Med Oral Pathol Oral Radiol. 2013;116:485-9.

6. Collet E, Jeudy G, Dalac S. Cheilitis, perioral dermatitis and contact allergy. Eur J Dermatol. 2013;23:303-7.

7. Oakley A. Cheilitis [Internet]. 2010 [cited 2019 September 17]. Available from: https://www.dermnetnz.org/topics/cheilitis/.

8. Cohen BA. Pediatric dermatology. 4th ed. Philadelphia: Elsevier Health Scienc es; 2013.

9. Cohen DE, de Souza A. Irritant contact dermatitis. In: Bolognia JL, Jorizzo JL, Schaffer JV, editors. Dermatology. 3rd ed. Vol. 1. Philadelphia: Elsevier/Saunders; 2012, p. 249-59.

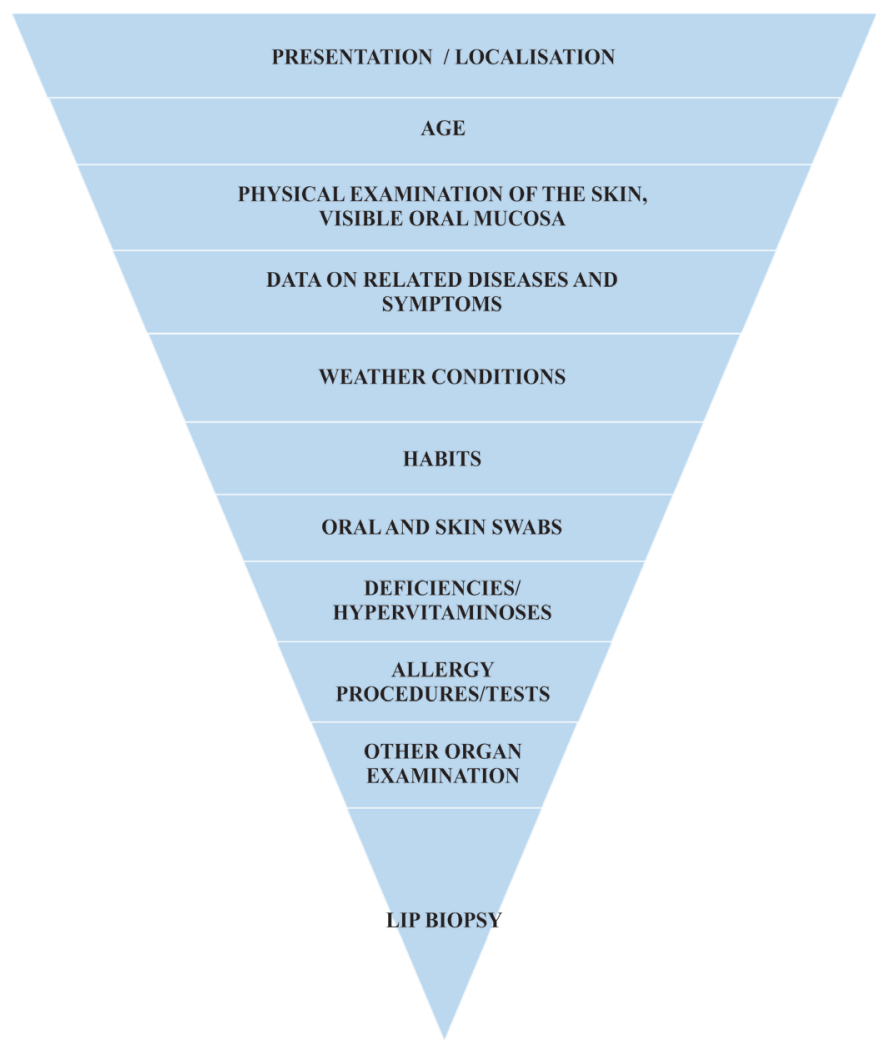

Figure 4 | Diagnostic management of patients.

\section{Conclusions}

In correctly diagnosing and managing the different types of cheilitis, practitioners must consider several factors, including the visible manifestations of the disease, related diseases and symptoms, personal habits and weather conditions, allergies, nutritional deficiencies, and results from tissue swabs and biopsies as necessary. We believe that our classification system would be of great benefit to researchers, patients, and doctors by simplifying both nomenclature and disease recognition and diagnosis, thus hastening and ensuring timely and adequate treatment. In addition, we hope that future studies will refer to our work, leading to even more precise terminology, diagnoses, and targeted treatments.

10. Scully C. The oral cavity and lips. In: Griffiths C, Barker J, Bleiker T, Chalmers R, Creamer D, editors. Rook's textbook of dermatology. 7th ed. Oxford: Blackwell Science; 2004. p. 66.1-66.121.

11. Greenberg SA, Schlosser BJ, Mirowski GW. Diseases of the lips. Clin Dermatol. 2017;35:1-14.

12. Woo SB. Biology and pathology of the oral caity. In: Goldsmith LA, Katz SI, Gilchrest BA, Paller AS, Leffel DJ, Wolff K, editors. Fitzpatrick's dermatology in general medicine. 8th ed. New York: McGraw Hill Medical; 2012. p. 1:827-52.

13. Lu S, Wu H. Initial diagnosis of anemia from sore mouth and improved classification of anemias by HCV and RDW in 30 patients. Oral Surg Oral Med Oral Pathol Oral Radiol Endod. 2004;98:679-85.

14. Bakula A, Lugovic-Mihic L, Šitum M, Turčin J, Šinković A. Contact allergy in the mouth: diversity of clinical presentations and diagnosis of common allergens relevant to dental practice. Acta Clin Croat. 2011;50:553-61.

15. Thappa DM. Clinical pediatric dermatology. Noida, Uttar Pradesh, India: Elsevier; 2012.

16. James WD, Berger TG, et al. Andrews' diseases of the skin. Clinical dermatology. Philadelphia: Saunders, Elsevier; 2006.

17. Bork K, Hoede N, Korting G, Burgdorf WHC, Young SK. Diseases of the oral mucosa and the lips. Philadelphia: W.B. Saunders; 1996. 
18. Oza N, Doshi JJ. Angular cheilitis: a clinical and microbial study. Indian J Dent Res. 2017;28:661-5.

19. Ayesh MH. Angular cheilitis induced by iron deficiency anemia. Cleve Clin J Med. 2018;85:581-2.

20. Park KK, Brodell RT, Helms SE. Angular cheilitis, part 2: nutritional, systemic, and drug-related causes and treatment. Cutis. 2011;88:27-32.

21. Terai $\mathrm{H}$, Shimahara $\mathrm{M}$. Cheilitis as a variation of Candida-associated lesions. Oral Dis. 2006;12:349-52.

22. Cross DL, Short LJ. Angular cheilitis occurring during orthodontic treatment: a case series. J Orthod. 2008;35:229-33.

23. Schlosser BJ, Pirigyi M, Mirowski GW. Oral manifestations of hematologic and nutritional diseases. Otolaryngol Clin North Am. 2011;44:183-203.

24. Rademaker M. Adverse effects of isotretinoin: a retrospective review of 1743 patients started on isotretinoin. Australas J Dermatol. 2010;51:248-53.

25. Samad A, Mohan N, Balaji RV, Augustine D, Patil SG. Oral manifestations of Plummer-Vinson syndrome: a classic report with literature review. J Int Oral Health. 2015;7:68-71.

26. Goel K, Sardana K. Herpetic cheilitis. Indian J Med Re. 2015;142:229-30.

27. Lim SW, Goh CL. Epidemiology of eczematous cheilitis at a tertiary dermatological referral centre in Singapore. Contact Dermatitis. 2000;43:322-6.

28. O'Gorman SM, Torgerson RR. Contact allergy in cheilitis. Int J Dermatol. 2016;55: 386-91.

29. Schena D, Fanntuzi F, Girolomoni G. Contact allergy in chronic eczematous lip dermatitis. Eur J Dermatol. 2008;18:688-92.

30. Griggs J, Almohanna H, Ahmed A, Ren S, Tosti A. "Fresh breath" on toothpaste: peppermint as cause of cheilitis. Dermatitis. 2019;30:74-5.

31. Zoli V, Silvani S, Vincenzi C, Tosti A. Allergic contact cheilitis. Contact Dermatitis. 2006;54:296-7.

32. Pascoe D, Moreau L, Sasseville D. Emergent and unusual allergens in cosmetics. Dermatitis. 2010;21:127-37.

33. Nyman G, Hagvall L. A case of allergic contact cheilitis caused by propolis and honey. Contact Dermatitis. 2016;74:186-7.

34. Milanesi N, Gola M, Verdelli A, Francalanci S. Aspects of contact cheilitis: analysis of 38 cases. J Eur Acad Dermatol Venereol. 2016;30:1052-3.

35. Budimir J, Mravak-Stipetić M, Bulat V, Ferček I, Japundžić I, Lugović-Mihić L. Allergic reactions in oral and perioral diseases-what do allergy skin test results show? Oral Surg Oral Med Oral Pathol Oral Radiol. 2019;127:40-8.

36. Girijala RL, Falkner R, Dalton SR, Martin BD. Exfoliative cheilitis as a manifestation of factitial cheilitis. Cureus. 2018;10:e2565.

37. Mani SA, Shareef BT. Exfoliative cheilitis: report of a case. J Can Dent Assoc. 2007;73:629-32.

38. Schwarz I, Bokanovic D, Aberer W. Mucosal diseases from an allergological perspective. Hautarzt. 2016;67:780-5.

39. Costa CS, Bagatin E, Martimbianco ALC, da Silva EM, Lúcio MM, Magin P, et al. Oral isotretionin for acne. Cochrane Database Syst Re. 2018;11:CDoo9435.

40. Jadotte YT, Schwartz RA. Solar cheilosis: an ominous precursor: part I. Diagnostic insights. J Am Acad Dermatol. 2012;66:173-84.

41. Kaugars GE, Pillion T, Svirsky JA, Page DG, Burns JC, Abbey LM. Actinic cheilitis: a review of 152 cases. Oral Surg Oral Med Oral Pathol Oral Radiol Endod. 1999; 88:181-6.

42. Rodríguez-Blanco I, Flórez Á, Paredes-Suárez C, Rodríguez-Lojo R, González-Vilas D, Rámirez-Santos A, et al. Actinic cheilitis: analysis of clinical subtypes, risk factors and associated signs of actinic damage. Acta Derm Venereol. 2019;99: 931-2.

43. Pilati S, Bianco BC, Vieira D, Modolo F. Histopathologic features in actinic cheilitis by the comparison of grading dysplasia systems. Oral Dis. 2017;23:219-24.

44. de Souza Lucena EE, Costa DC, da Silveira EJ, Lima KC. Prevalence and factors associated to actinic cheilitis in beach workers. Oral Dis. 2012;18:575-9.

45. Carvalho MV, de Moraes SLD, Lemos CAA, Santiago Júnior JF, Vasconcelos BCDE, Pellizzer EP. Surgical versus non-surgical treatment of actinic cheilitis: a systematic review and meta-analysis. Oral Dis. 2019;25:972-81.

46. Hassona Y, Quatachi T. A bibliometric analysis of the most cited articles about squamous cell carcinoma of the mouth, lips and oropharynx. Oral Surg Oral Med Oral Pathol Oral Radiol Endod. 2019;128:25-32.

47. Vieira RA, Minicucci EM, Marques ME, Marques SA. Actinic cheilitis and squamous cell carcinoma of the lip: clinical, histopathological and immunogenetic aspects. An Bras Dermatol. 2012;87:105-14.
48. das Chagas E Silva de Carvalho LF, Pereira TM, Magrini TD, Cavalcante AS, da Silva Martinho H, Almeida JD. Optical diagnosis of actinic cheilitis by infrared spectroscopy. Photodiagnosis Photodyn Ther. 2016;16:27-34.

49. Critchlow WA, Chang D. Cheilitis granulomatosa: a review. Head Neck Pathol. 2014;8:209-13.

50. McCartan BE, Healy CM, McCreary CE, Flint SR, Rogers S, Toner ME, et al. Characteristics of patients with orofacial granulomatosis. Oral Dis. 2011;17:696-704.

51. Miest R, Bruce A, Rogers RS 3rd. Orofacial granulomatosis. Clin Dermatol. 2016; 34:505-13.

52. Howell JL, Bussell RM, Hegarty AM, Zaitoun H. Service evaluation of patients with orofacial granulomatosis and patients with oral Crohn's disease attending a paediatric oral medicine clinic. Eur Arch Paediatr Dent. 2012;13:191-6.

53. Elias MK, Mateen FJ, Weiler CR. The Melkersson-Rosenthal syndrome: a retrospective study of biopsied cases. J Neurol. 2013; 260:138-43.

54. Ko CJ, Glusac EJ, Shapiro PE. Noninfectious granulomas. In: Elder D, Elenitsas R Johnson BL, et al., editors. Lever's histopathology of the skin. 10th ed. Philadelphia: Wolters Kluwer-Lippincott Williams \& Wilkins; 2009. p. 361-88.

55. Vasconcelos ACU, Loyola AM, Gomes APN, de Araújo VC, Tarquínio SBC, Silveira FM, et al. A symptomatic swelling of the upper lip. Oral Surg Oral Med Oral Pathol Oral Radiol. 2018;125:107-11.

56. Carrington PR, Horn TD. Cheilitis glandularis: a clinical marker for both malignancy and/or severe inflammatory disease of the oral cavity. J Am Acad Dermatol. 2006;54:336-7.

57. Leão JC, Ferreria AM, Martins S, Jardim ML, Barret AW, Scully C, et al. Cheilitis glandularis: an unusual presentation in a patient with HIV infection. Oral Surg Oral Med Oral Pathol Oral Radiol Endod. 2003;95:142-4.

58. Andrade ES, Sobral AP, Laureano Filho JR, Santos ME, Camargo IB. Cheilitis glandularis and actinic cheilitis: differential diagnoses-report of three unusual cases. Dermatol Online J. 2009;15:5.

59. Friedrich RE, Löning T. Cheilitis glandularis: case report with respect to immunohistochemical findings. GMS Interdiscip Plast Reconstr Surg DGPW. 2016;5: Doco4.

6o. Nico MM, Nakano de Melo J, Lourenço SV. Cheilitis glandularis: a clinicopathological study in 22 patients. J Am Acad Dermatol. 2010;62:233-8.

61. Reiter S, Vered M, Yarom N, Goldsmith C, Gorsky M. Cheilitis glandularis: clinico-histopathological diagnostic criteria. Oral Dis. 2011;17:335-59.

62. Stoopler ET, Carrasco L, Stanton DC, Pringle G, Sollecito TP. Cheilitis glandularis: an unusual histopathologic presentation. Oral Surg Oral Med Oral Pathol Oral Radiol Endod. 2003;95:312-7.

63. Dos Santos HT, Cunha JLS, Santana LAM, Trento CL, Marquetti AC, de Albuquerque-Júnior RLC, et al. Plasma cell cheilitis: the diagnosis of a disorder mimicking lip cancer. Autops Case Rep. 2019;9:e2018075.

64. Sarkar S, Ghosh S, Sengupta D. Clinically granulomatous cheilitis with plasma cells. Indian Dermatol Online J. 2016;7:96-8.

65. Farrier JN, Perkins CS. Plasma cell cheilitis. Br J Oral Maxillofac Surg. 2008;46: 679-80.

66. Liu W, Shen ZY, Wang LJ, Hu YH, Shen XM, Zhou ZT, et al. Malignant potential of oral and labial chronic discoid lupus erythematosus: a clinicopathological study of 87 cases. Histopathology. 2011;59:292-8.

67. Arvanitidou IE, Nikitakis NG, Georgaki M, Papadogeorgakis N, Tzioufas A, Sklavounou A. Multiple primary squamous cell carcinomas of the lower lip and tongue arising in discoid lupus erythematosus: a case report. Oral Surg Oral Med Oral Pathol Oral Radiol. 2018;125:22-30.

68. Baglama Š, Trčko K, Rebol J, Miljković J. Oral manifestations of autoinflammatory and autoimmune diseases. Acta Dermatovenerol Alp Pannonica Adriat. 2018;27: 9-16.

69. Lugović-Mihić L, Bukvić I, Bulat V, Japundžić I. Factors contributing to chronic urticaria/angioedema and nummular eczema resolution-which findings are crucial? Acta Clin Croat. 2019;58:595-603.

70. Feily A, Pazyar N, Rafeie E, Khazanee A, Namazi MR. An unusually large squamous cell carcinoma mass arising from the lower lip. Acta Dermatovenerol Alp Pannonica Adriat. 2010;19:43-4. 